\title{
Trends in Biopharmaceutical Alliances for the Key Business Models
}

\author{
Working Paper No. 37
}

Bruce Rasmussen

\section{Pharmaceutical Industry Project Working Paper Series}

December 2007

Centre for Strategic Economic Studies

Victoria University of Technology

PO Box 14428 Melbourne VIC 8001 AUSTRALIA

Telephone +61399191340

Fax +61399191350

Contact email: bruce.rasmussen@vu.edu.au 


\title{
Trends in Biopharmaceutical Alliances for the Key Business Models
}

\author{
Bruce Rasmussen
}

\section{Introduction}

Earlier work (Rasmussen 2006) served to emphasise the much increased importance of alliances in the period since 1990, illustrating the growth in their number and the payout values attached to them. The major role of alliances in the transfer of technologies and the discernable difference between platform technology and drug discovery technology alliances supports the distinction, between two biopharmaceutical business models based on two different technological regimes.

Orsengio et al. (2001) suggest that two technologically based search regimes are distinguishable in biopharmaceutical research:

The first regime is essentially based on biological hypotheses and molecules that tend to be specific to given fields of application (co-specialised technologies), while the second regime is characterised by the emergence of new generic tools (transversal technologies). (Orsengio et al. 2001, p488)

Examples of co-specialised technologies include recombinant DNA, interferons and monoclonal antibodies. Each of these technologies has been derived from a new set of scientific hypotheses that have produced a particular class of drugs. They are referred to here as drug discovery technologies. On the other hand, transversal technologies are generic, providing a common platform for a range of drug discovery and development projects. They are referred to as platform technologies, such as high throughput screening, combinatorial chemistry, gene expression and sequencing. This paper examines alliances formed by firms representing these two distinct biopharmaceutical business models, drug discovery and platform technology, based on two the different technological regimes.

The major role of pharmaceutical firms in forming alliances to obtain new technologies is also considered. It was suggested in Rasmussen (2007a) that the fragmentation of expertise in the industry had presented challenges to pharmaceutical firms. One response was to expand their own value chains by forming alliances with biopharmaceutical firms to access these new technologies. This paper examines the types of platform and drug discovery technologies accessed by large pharmaceutical companies through alliances.

The alliances between four classes of companies which have formed discernibly different models are considered in this paper. These are large pharmaceutical companies (see Rasmussen 2007a), drug discovery companies, platform technology companies and 'large biotechs'. 'Large biotechs' are biopharmaceutical companies that have more diversified operations than the specialist companies and have adopted fully integrated business models analogous to the large pharmaceutical companies.

The different alliance formation patterns of these four sets of firms are used to demonstrate the different roles played by these firms in the biopharmaceutical value 
network. For instance there are differences in the alliance formation patterns between platform and drug discovery companies that go to the heart of the different business models of such firms. The significant contribution of large pharmaceutical companies, both to the development of platform technologies and new drugs, is also evident from their alliance formation activity.

\section{The companies included in each business model}

The four groups of firms to be analysed are the top 10 pharmaceutical companies by sales, two groups of specialist biopharmaceutical firms listed in the US, which are tracked and classified according to their principal technologies by Recap ${ }^{1}$. The Recap classification enables this group of companies to be divided into two specialist groups, drug discovery and platform technology companies. The fourth group consists of the largest six biopharmaceutical companies which in this thesis will be called 'large biotechs'.

Table 1 below list the categories of companies for the two specialist groups together with the number in each. There are a total of 87 platform technology companies, 121 drug discovery companies, all of which are publicly listed in the US. Together these two groups of companies represent only about $8 \%$ of the biopharmaceutical companies with alliances listed on Recap for the years 1990, 1995, 2000 and 2005, but are involved in over $30 \%$ of the bio biotech alliances and almost $25 \%$ of the drug biotech alliances for those years.

Table 1 Number of platform and drug discovery companies classified by Recap company group

\begin{tabular}{lrrr}
\hline & Recap biopharmaceutical company groups & \\
\hline Platform Technology & No. of Companies & Therapeutic Group & No. of Companies \\
\hline 1st Generation Genomics & 5 & Autoimmune & 9 \\
Chemistry & 10 & Cancer & 44 \\
Delivery & 22 & Cardiovascular & 9 \\
Diagnostic/image & 21 & CNS & 15 \\
Genomic Supply & 10 & Infection & 17 \\
Genomic Targets & 12 & Metabolic & 11 \\
Screening & 7 & Wound & 4 \\
& & Gene/Cell therapy & 12 \\
Total platform technology & $\mathbf{8 7}$ & Total Therapeutic & $\mathbf{1 2 1}$ \\
\hline
\end{tabular}

They are by no means a representative sample, but rather a group of leading biopharmaceutical companies. Most are unprofitable and significantly smaller in size to the 'large biotechs'. Sixty per cent of the companies had a market capitalisation of between $\$ 100$ million and \$1 billion in December 2005. On average there is little difference in the average market capitalisation of the platform and drug discovery companies although average revenue of the platform technology companies is more than twice the average for drug discovery companies.

${ }^{1}$ www.signalsmag.com 
The six 'large biotechs' are Amgen, Biogen (now Biogen IDEC), Chiron, Genentech, Genzyme and Gilead Sciences2 which is also tracked by Recap. In this section their alliance patterns will be analysed and compared with the top pharmaceutical companies to view the extent of their convergence.

The pharmaceutical companies selected for analysis of their alliances are the top 10 by sales in 2005 (see Table 2).

Table 2 Top 10 pharmaceutical companies by sales, 2005

\begin{tabular}{lc}
\hline Company & Pharma Sales (\$ billions) \\
\hline Pfizer & 44.28 \\
Glaxo & 33.96 \\
Sanofi-Aventis & 32.24 \\
Novartis & 24.96 \\
Astrazeneca & 23.95 \\
J\&J & 22.32 \\
Merck & 22.01 \\
Wyeth & 15.32 \\
BMS & 15.25 \\
\hline Lilly & 14.65 \\
\hline
\end{tabular}

\section{Alliance formation trends for the selected biopharmaceutical and pharmaceutical firms ${ }^{3}$}

Tables 3 and 4 provide an overview of the alliance formation trends of these companies, both in terms of alliance numbers and payout values.

Table 3 Number of alliances formed at five-year intervals by company type, 1990 to 2005

\begin{tabular}{llrrrr}
\hline Type & Role & $\mathbf{1 9 9 0}$ & $\mathbf{1 9 9 5}$ & $\mathbf{2 0 0 0}$ & $\mathbf{2 0 0 5}$ \\
\hline Drug Disc & Client & 4 & 19 & 67 & 57 \\
& Developer & 50 & 68 & 131 & 107 \\
\hline Platform & Client & 2 & 8 & 80 & 49 \\
& Developer & 40 & 76 & 242 & 133 \\
\hline Large & Client & 7 & 22 & 25 & 28 \\
biotech & Developer & 15 & 7 & 17 & 10 \\
\hline Large & Client & 50 & 151 & 214 & 184 \\
Pharma & Developer & & 19 & 11 & 14 \\
\hline
\end{tabular}

Table 3 shows the number of alliances formed by the selected companies in their role as both client and developer. The overwhelming majority of alliances formed by large pharma is in the role of client, in which it contracts with other companies to obtain technologies or other complementary assets. Over the period, the number of alliances

\footnotetext{
${ }^{2}$ Medimmune has been recently included in this group of companies by Recap but has yet to become profitable. Previously it was classified in the 'infection' category and has been so classified in this analysis. Chiron has recently been acquired by Novartis but was independent for the period of this analysis.

${ }^{3}$ The source of alliance data is Recombinant Capital (www.recap.com) which has been discussed in earlier PIP Working Papers (see for instance Rasmussen 2002).
} 
formed has increased substantially from 50 in 1990 to 184 in 2005. On the other hand, in 1990, the large biotechs were forming more alliances in the role of developer than client. By 1995 this had switched to the majority being as client, as the larger biotechs began to adopt a role more analogous to large pharma. However even allowing for their smaller number, six versus ten, the number of alliances per firm is significantly smaller than the top pharma companies.

Both the drug discovery and platform technology companies have formed a far greater number of alliances as developer than as client. While this gap has closed for the drug discovery companies, the primary role of the platform companies is as a developer. The drug discovery companies included here are the larger more successful ones, and presumably their role has evolved over the period, to one in which they have the senior, or client role, in a larger number of their alliances.

The payout values for these alliances shown in Table 4 serve to emphasise the patterns illustrated by the number of alliances formed and shown in Table above. Of greatest significance is the size of the payouts by large pharma in their role as client, which increased from \$459.6 million in 1990 to $\$ 10,825$ million in 2005. By contrast, the payout amount by large biotechs in 2005 was only \$1,274 million, indicative of a much smaller role in resource transfers to developer companies through alliances. The Recap listed drug discovery and platform technology companies were major recipients of alliance payout commitments as developers, with developer payouts of $\$ 4.2$ billion each in 2005. About $46 \%$ of the amount committed to these drug discovery companies and $52 \%$ of the amount for platform companies was committed by the large pharmaceutical companies.

Table 4 Payout values for alliances formed at five-year intervals by company type, 1990 to 2005 (\$ million)

\begin{tabular}{llrrrr}
\hline Type & Role & $\mathbf{1 9 9 0}$ & $\mathbf{1 9 9 5}$ & $\mathbf{2 0 0 0}$ & $\mathbf{2 0 0 5}$ \\
\hline Drug Disc & Client & 2.8 & 25.4 & 309.7 & 1141.3 \\
& Developer & 242.2 & 856.8 & 1738.4 & 4184.8 \\
Platform & Client & 0.3 & 2.5 & 293.3 & 167.5 \\
& Developer & 174.4 & 1237.7 & 2430.9 & 4221.6 \\
Large & Client & 116.8 & 428.3 & 576.7 & 1274.1 \\
biotech & & & & & \\
& Developer & 22.6 & 276.0 & 83.0 & 640.0 \\
Large & Client & 459.6 & 2952.1 & 4861.6 & 10825.0 \\
Pharma & & & & & \\
& Developer & & 142.8 & 2890.1 & 32.0 \\
\hline
\end{tabular}

The annual average number of alliances formed per company was analysed (see Table 5) and found to be relatively constant for the specialist firms but alliances involving pharmaceutical companies have been increasing.

Table 5 Average number of alliances formed by type of company, 1990 to 2005

\begin{tabular}{lrrrr}
\hline & 1990 & 1995 & 2000 & 2005 \\
\hline Drug disc. & 1.3 & 1.5 & 1.7 & 1.6 \\
Platform & 1.0 & 1.0 & 1.9 & 1.6 \\
Large biotech & 2.3 & 5.5 & 4.2 & 4.7 \\
Large pharma & 6.3 & 15.1 & 21.4 & 18.4 \\
\hline
\end{tabular}


The top 10 pharmaceutical companies increased their rate of alliance formation from an average per company of 6.3 in 1990 to 18.4 in 2005. This is consistent with expectations of behaviour of the pharmaceutical business model. One of the anticipated responses of the large pharmaceutical firms to biotechnology is a growing trend in alliance formation per firm, as increasing access is sought to the new technologies.

Large biotechs also increased their average number of alliances from 2.3 to 4.7. Both the drug discovery and platform companies increased their rate of alliance formation to a modest extent, from 1.3 and 1.0 respectively to 1.6. These results suggest the increasing trend in alliance formation was mainly explained by an increasing number of biopharmaceutical firms forming alliances.

\section{Interdependencies between business models}

As noted above, the classification of many of the alliances by type of company business model provides an opportunity to examine the interdependencies between the four business models. Table 6 shows the number of alliances cross tabulated by role (client or developer) and type of company. The client role is listed down the column and that of developer by row. For instance it shows that large pharmaceutical companies, in their client role, formed 59 alliances with drug discovery companies, 79 alliances with platform companies 8 with large biotechs, 10 with other large pharmas and 443 with companies not classified, that is neither included in the Recap list of biotechs or as one of the top 10 large pharma companies. In their role as developer, platform companies have formed 10 alliances with drug discovery companies 27 with platform companies, 9 with large biotechs, 79 with large pharma and 366 not classified.

Table 6 Total number of alliances by role and type of company for years 1990, 1995, 2000, 2005

\begin{tabular}{lcccccc}
\hline \multicolumn{7}{c}{ Developer } \\
\hline Client & Drug disc & Platform & Large biotech & Large pharma & Not classified & Total developer \\
\hline Drug disc. & 14 & 10 & 3 & & 120 & 147 \\
Platform & 13 & 27 & 3 & & 96 & 139 \\
Large biotech & 15 & 9 & 3 & & 55 & 82 \\
Large pharma & 59 & 79 & 8 & 10 & 443 & 599 \\
Not classified & 255 & 366 & 32 & 34 & & 687 \\
\hline Total client & 356 & 491 & 49 & 44 & 714 & 1654 \\
\hline
\end{tabular}

There are a number of features of Table 6 . The first is the large number of developer alliances formed by platform companies (491). A high proportion of these are with companies not classified, but of those that are, 79 are with large pharma. By comparison, large pharma have formed only 59 alliances with drug discovery companies, indicating the high relative demand from large pharma companies for platform technologies. The second is the relatively large number of alliances formed between platform companies (27) which is indicative of the specialised nature of the platform technology companies and the need for collaboration between such firms to produce marketable products. About half of these alliances involve three technologies, screening, gene expression and sequencing. 
The third is that compared with large pharma, the large biotechs, as client, have relatively more alliances with drug discovery, than with platform companies. As will be illustrated below this reflects a greater focus on cancer and consequently a greater interest in monoclonals alliances than large pharma.

These three features are given sharp relief by Table 7, which shows the payout values for alliances by role and type of company for the total period. In particular, the large payout values for alliances between large pharma and platform companies emphasises the value of such alliances to large pharma. The relatively small amount committed in alliances by the non-pharmaceutical companies, including large biotechs, is also very evident. While there were a relatively large number of alliances formed between the platform companies the total value of alliance commitments is low.

Table 7 Total payout values for alliances by role and type of company for years 1990 , 1995, 2000, 2005

\begin{tabular}{lrrrrrr}
\hline \multicolumn{7}{c}{ Developer } \\
\hline Client & Drug disc & Platform & Large biotech & Large pharma & Not classified & Total developer \\
\hline Drug disc. & 331.7 & 544.5 & & & 603.0 & 1479.1 \\
Platform & 39.3 & 166.8 & & & 257.5 & 463.6 \\
Large biotech & 522.2 & 180.7 & & & 1692.9 & 2395.8 \\
Large pharma & 3235.8 & 4165.4 & 298.5 & 1771.0 & 9627.6 & 19098.2 \\
Not classified & 2893.3 & 3007.2 & 723.1 & 1293.9 & & 7917.5 \\
\hline Total client & 7022.2 & 8064.6 & 1021.6 & 3064.9 & 12180.9 & 31354.2 \\
\hline
\end{tabular}

These results serve to illustrate the importance of alliances to the large pharmaceutical firms relative to the other types of firms, particularly platform technologies which are larger both in number and value of payout. This suggests that platform technologies that assist large pharmaceutical firms with their own drug discovery and development programs are at least as significant as accessing the new drug discovery technologies, The analysis below of the individual technologies provides further evidence of this.

\section{Technology and disease focus of the different business models}

Table 8 shows the breakdown of alliances by technology group for each of the business models. The alliance technologies of large pharma and large biotechs are shown only in their role as client, given their relatively minor role as developer. For large pharma, of the alliances classified, the ratio of platform to drug discovery alliances is 3.4 to 1 . Over half of their total alliances are in platform technologies and these are relatively well spread. Similarly for its drug technology alliances, none are particularly focussed on a specific drug discovery technology.

Large pharma companies have a much greater focus on platform technologies than large biotechs. Over 53\% of large pharma alliance technologies involve platform technologies compared with only $38.4 \%$ for large biotechs. Interest in bioinformatics, screening and a range of genomics based technologies is higher than for large biotechs. Large pharma has no focus on one drug technology in particular. The proportion of only $4.5 \%$ on monoclonals is in stark contrast to large biotechs with $18.2 \%$ in monoclonals and $38.4 \%$ in drug discovery technologies compared with only $15.5 \%$ for large pharma. The drug discovery companies as clients appear to have a very strong need for drug delivery technologies (16.7\%) and monoclonals (28.9\%). 
Platform technology alliances, as would be expected are less focused on particular disease areas than drug discovery alliances. Table 8 shows that platform technology companies have $64.5 \%$ of their alliance technologies involved in platform technologies and only $13.5 \%$ involving drug discovery. The platform technologies are broadly distributed, but with genomics based technologies a high proportion of the total. Drug discovery companies have $37.3 \%$ of their alliance technologies in drug discovery technologies, almost $20 \%$ involve no technology and only $21.5 \%$ involve a platform technology of which recombinant DNA and screening appear to be the most important.

Table 8 Alliance technologies by role and business model type (\%)

\begin{tabular}{|c|c|c|c|c|c|c|}
\hline \multirow[b]{2}{*}{ Technology Group } & \multicolumn{4}{|c|}{ Role as client } & \multicolumn{2}{|c|}{ Role as developer } \\
\hline & $\begin{array}{r}\text { Large } \\
\text { Pharma }\end{array}$ & $\begin{array}{r}\text { Large } \\
\text { Biotech }\end{array}$ & Drug Disc & Platform & Drug Disc & Platform \\
\hline \multicolumn{7}{|l|}{ Platform } \\
\hline Bioinformatics & $6.1 \%$ & $2.0 \%$ & $2.0 \%$ & $5.4 \%$ & $0.3 \%$ & $2.4 \%$ \\
\hline Combinatorial & $3.8 \%$ & $4.0 \%$ & $3.4 \%$ & $2.0 \%$ & $0.6 \%$ & $3.7 \%$ \\
\hline DNA Probes & $0.3 \%$ & $2.0 \%$ & $0.0 \%$ & $2.9 \%$ & $0.3 \%$ & $3.2 \%$ \\
\hline Drug Delivery & $9.2 \%$ & $3.0 \%$ & $10.7 \%$ & $5.4 \%$ & $4.2 \%$ & $9.0 \%$ \\
\hline Gene Expression & $7.9 \%$ & $4.0 \%$ & $4.7 \%$ & $16.7 \%$ & $1.8 \%$ & $16.0 \%$ \\
\hline Gene Sequencing & $3.1 \%$ & $0.0 \%$ & $0.7 \%$ & $8.3 \%$ & $0.3 \%$ & $7.3 \%$ \\
\hline Microarrays & $1.7 \%$ & $0.0 \%$ & $0.0 \%$ & $6.4 \%$ & $0.0 \%$ & $7.3 \%$ \\
\hline Pharmacogenomics & $2.1 \%$ & $1.0 \%$ & $0.0 \%$ & $2.5 \%$ & $0.6 \%$ & $2.4 \%$ \\
\hline Proteomics & $2.4 \%$ & $0.0 \%$ & $1.3 \%$ & $2.5 \%$ & $0.3 \%$ & $2.0 \%$ \\
\hline Rational Drug Design & $2.1 \%$ & $0.0 \%$ & $0.7 \%$ & $1.0 \%$ & $0.9 \%$ & $1.6 \%$ \\
\hline Recombinant DNA & $3.2 \%$ & $13.1 \%$ & $2.7 \%$ & $2.5 \%$ & $7.5 \%$ & $1.0 \%$ \\
\hline Screening & $11.3 \%$ & $9.1 \%$ & $6.7 \%$ & $7.8 \%$ & $4.8 \%$ & $8.5 \%$ \\
\hline Total selected platform & $53.1 \%$ & $38.4 \%$ & $32.9 \%$ & $63.2 \%$ & $21.5 \%$ & $64.5 \%$ \\
\hline \multicolumn{7}{|l|}{ Drug discovery } \\
\hline Cell therapy & $0.8 \%$ & $6.1 \%$ & $0.7 \%$ & $1.0 \%$ & $3.0 \%$ & $0.9 \%$ \\
\hline Monoclonals & $4.5 \%$ & $18.2 \%$ & $28.9 \%$ & $6.9 \%$ & $19.7 \%$ & $3.6 \%$ \\
\hline Oligonucleotides & $4.0 \%$ & $6.1 \%$ & $1.3 \%$ & $4.4 \%$ & $2.1 \%$ & $5.6 \%$ \\
\hline Peptides & $2.1 \%$ & $3.0 \%$ & $2.0 \%$ & $1.5 \%$ & $6.3 \%$ & $1.3 \%$ \\
\hline Vaccines & $4.0 \%$ & $5.1 \%$ & $4.0 \%$ & $1.0 \%$ & $6.3 \%$ & $2.1 \%$ \\
\hline Total selected drug disc & $15.5 \%$ & $38.4 \%$ & $36.9 \%$ & $14.7 \%$ & $37.3 \%$ & $13.5 \%$ \\
\hline Other & $19.5 \%$ & $17.2 \%$ & $12.1 \%$ & $11.8 \%$ & $21.8 \%$ & $12.8 \%$ \\
\hline No technology & $11.9 \%$ & $6.1 \%$ & $18.1 \%$ & $10.3 \%$ & $19.4 \%$ & $9.3 \%$ \\
\hline Grand Total & $100.0 \%$ & $100.0 \%$ & $100.0 \%$ & $100.0 \%$ & $100.0 \%$ & $100.0 \%$ \\
\hline Total no of alliances & 717 & 99 & 149 & 204 & 335 & 698 \\
\hline
\end{tabular}

In Table 6 it was noted that a good proportion of platform technology alliances were between platform technology companies. The alliance patterns between the platform companies as client and developer indicates a relative concentration of such alliances in the major platform technologies, such as gene expression and sequencing, drug delivery and screening. This suggests that networks of platform technologies provide mutual support in specialist technologies. Platform technology companies specialising in a particular technology will form a dense support network with other platform technology companies specialising in the same technology. These patterns are very consistent with those of the open innovation paradigm discussed in Rasmussen (2007b). 


\section{Disease focus of alliance technologies by business model type}

Table 9 shows the alliances classified by first named disease. It helps confirm the widely differentiated roles of the four business models. Platform technology companies are not disease specialised, whereas $81.7 \%$ of alliance technologies of drug discovery companies, as developer, are focussed on a particular disease, most importantly cancer. The pattern of alliances formed by large pharma also tends not to be particularly disease focussed, with $42.3 \%$ of alliance technologies not disease related. In contrast large biotechs are much more disease focussed with only $30.4 \%$ of alliance technologies not disease related and correspondingly high proportion of alliance technologies focussed on cancer.

Table 9 Alliances by disease and company role and business model type (\%)

\begin{tabular}{lrrrrrr}
\hline & \multicolumn{3}{c}{ Role as client } & \multicolumn{3}{c}{ Role as developer } \\
\hline Disease group & $\begin{array}{r}\text { Large } \\
\text { Pharma }\end{array}$ & $\begin{array}{r}\text { Large } \\
\text { Biotech }\end{array}$ & Drug Disc & Platform & Drug Disc & Platform \\
Anti-inflammatory & $3.9 \%$ & $2.7 \%$ & $1.1 \%$ & $2.1 \%$ & $2.7 \%$ & $2.0 \%$ \\
Autoimmune & $3.7 \%$ & $4.5 \%$ & $2.2 \%$ & $2.1 \%$ & $5.8 \%$ & $3.5 \%$ \\
Cancer & $10.3 \%$ & $18.8 \%$ & $28.6 \%$ & $9.8 \%$ & $27.2 \%$ & $11.1 \%$ \\
Cardiovascular & $5.4 \%$ & $2.7 \%$ & $1.1 \%$ & $1.3 \%$ & $4.1 \%$ & $4.7 \%$ \\
CNS & $6.0 \%$ & $6.3 \%$ & $4.4 \%$ & $3.0 \%$ & $8.4 \%$ & $4.3 \%$ \\
Infection & $9.2 \%$ & $10.7 \%$ & $17.6 \%$ & $6.0 \%$ & $14.9 \%$ & $8.4 \%$ \\
Metabolic Disorders & $2.9 \%$ & $1.8 \%$ & $0.0 \%$ & $0.9 \%$ & $2.7 \%$ & $1.6 \%$ \\
Pain & $1.3 \%$ & $0.0 \%$ & $0.0 \%$ & $0.0 \%$ & $1.0 \%$ & $0.5 \%$ \\
Other & $15.1 \%$ & $22.3 \%$ & $12.6 \%$ & $9.4 \%$ & $14.9 \%$ & $15.9 \%$ \\
No disease & $42.3 \%$ & $30.4 \%$ & $32.4 \%$ & $65.4 \%$ & $18.3 \%$ & $48.0 \%$ \\
Grand Total & $100.0 \%$ & $100.0 \%$ & $100.0 \%$ & $100.0 \%$ & $100.0 \%$ & $100.0 \%$ \\
\hline
\end{tabular}

\section{Conclusions}

The strong interdependencies between the types of firms are evident in the formation of the alliances. The large pharmaceutical companies have formed a relatively large number of alliances with platform companies and committed to a higher value of alliance payouts than to the group of drug discovery companies. This indicates a higher level of interest in acquiring platform technologies than drug discovery technologies, at least from the two groups of companies for which this distinction is available. Any conclusion about comparative interest has to be qualified by the large of number alliances with other unclassified biopharmaceutical firms.

The analysis has also demonstrated the high level of interdependency between platform companies. This confirms the importance of technology exchange between specialist platform companies to develop marketable products. The alliances indicate that screening, gene expression and sequencing are the major technologies of joint interest to the platform technology companies.

The comparison between large pharma and large biotechs indicates significant continuing differences. In particular, large biotechs show a relatively low level of interest in platform technologies. Even if some aspects of the two business models are drawing closer, the alliance formation by large biotechs, as with their smaller drug discovery cousins, indicates a stronger interest in cancer and infection than the pharmaceutical companies. 
In contrast, as noted, large pharma have a much broader disease interest and a more intense interest in a wide range of platform technologies. This reflects more complex pharmaceutical development pipelines. Large pharma companies have needed new platform technologies such as screening to improve the efficiency of their existing drug discovery processes. They have also needed access to the newer genomics based technologies, which are more likely known in-house by the large biotechs. From their long history in the industry, the large pharma companies have a broad interest in disease, and therefore in all the drug discovery technologies that might assist these efforts. This contrasts with the focus of the large biotechs on the newer unsolved diseases of cancer and HIV/ADIS.

The significant role of the large pharmaceutical companies in funding a great diversity of alliances, with both platform and drug discovery companies, is again consistent with the role expected of them as they adjust their business models to biotechnology. It is noteworthy that more than half of large pharmaceutical company alliances involve platform technologies and only $15 \%$ involve the major selected drug technologies. This compares with an almost equal distribution between platform and drug discovery alliances by 'large' biopharmaceutical counterparts. Moreover the value of alliance payouts to platform technology companies exceeds that committed to drug discovery companies. This suggests that large pharmaceutical companies feel the need to develop their 'absorptive capacity' across a wide range of knowledge platforms. Each new platform technology has potential application to the complex range of therapeutic treatments being developed by the large pharmaceutical companies and one means of acquiring knowledge of the new technologies is through alliances with specialist platform companies. This hierarchical relationship between the pharmaceutical and platform technology companies is consistent with the 'markets in technology’ proposed by Arora et al. (2001).

Nonetheless pharmaceutical companies also have a strong interest in drug discovery technologies and some of the largest payouts are by pharmaceutical companies in alliances involving new drug discovery technologies focussed on particular diseases. It has been noted that the pharmaceutical companies have a broader interest in diseases and drug discovery technologies than their large biotech counterparts. Again this is evidence of the development of a broad based absorptive capacity

The large number of alliances between smaller companies, especially platform technology companies, demonstrates the development of a complex value network in platform and drug discovery technologies. It is indicative of support for the importance of the interdependencies between small specialist companies in the innovation process, as highlighted by Langlois (2003) and Rothwell (1994), in the search for complementary technology assets. It may also suggest a greater commoditisation of the biopharmaceutical platform technologies (Arora et al. 2001). Certainly some of these technologies have been used to build products, which makes it easier to package such technologies into expendable consumables, rather than licensing access to an information resource. The upward trend in alliances between platform companies underlies the willingness of such companies to participate in the innovation process through joint development in the search for 'relational rents'. 


\section{References}

Arora, A., Fosfuri, A. and Gambardella, A. 2001, Markets for Technology: The Economics of Innovation and Corporate Strategy, MIT Press, Cambridge, Mass.

Langlois, R. 2003, 'The vanishing hand: The changing dynamics of industrial capitalism', Industrial and Corporate Change, vol. 12, no. 2, pp. 351-338.

Orsenigo, L., Pammolli, F. and Riccaboni, M. 2001, 'Technological change and network dynamics: Lessons from the pharmaceutical industry’, Research Policy, vol. 30, pp. 485-508.

Rasmussen, B. 2002, 'The Role of Pharmaceutical Alliances', Pharmaceutical Industry Project Working Paper No. 2, June, CSES, Victoria University, Melbourne.

Rasmussen, B. 2006, 'Innovation and industry structure in the biomedical industry: Role of alliances', in B. Grewal and M. Kumnick (eds), Engaging the New World: Responses to the Knowledge Economy, Melbourne University Press, Melbourne.

Rasmussen, B. 2007a, 'Business Models and the Theory of the Firm’, Pharmaceutical Industry Project Working Paper No. 32, June, Centre for Strategic Economic Studies, Victoria University, Melbourne.

Rasmussen, B. 2007b, 'Open Innovation and the Networked Firm', Pharmaceutical Industry Project Working Paper No. 31, May, Centre for Strategic Economic Studies, Victoria University, Melbourne.

Rothwell, R. 1994, 'Towards the fifth-generation innovation process', International Marketing Review, vol. 11, no. 1, pp. 7-31. 